\title{
Are Learning Interaction or Assessment Accommodation Implementation Critical in Improving the Learning Performance for College Students with Special Needs?
}

\author{
Li Ju Chen ${ }^{*}$ \\ Chang Gung University \\ Graduate Institute of Early Intervention
}

\begin{abstract}
This study intended to identify if assessment accommodation or learning interaction are correlated with improving the students' learning performance. A questionnaire was administered to 288 Taiwanese college students with disabilities. The students were split into three groups: sensory special learning needs, physical special learning needs, and cognitive special learning needs. The study found that: (1) Various assessment accommodations were needed by the students with sensory and cognitive special learning needs. However, these accommodations were not critical for improving students' learning performance. (2) Learning interaction with teachers for assessment was the most critical correlated element for improving learning performance among students with special learning needs. Based on the research findings, assessment practices and further research implication are proposed.
\end{abstract}

Keywords: assessment accommodation, assessment modification, college students with learning needs, learning performance.

\section{Introduction}

In order to overcome the assessment difficulties encountered by students with disabilities, educational policies in many countries advocate assessment accommodation. McMenamin and Zirke (2003) surveyed students with disabilities in order to document their dissatisfaction about special education practices under the Americans with Disabilities Act and Section 504 of the Rehabilitation Act. The results showed that most cases involve dissatisfaction

* Corresponding author: Li Ju Chen, Associate Professor of Graduate Institute of Early Intervention, Chang Gung University, 259 Wenhua 1st Road, Kwei-shan, Tao-Yuan 33302, Taiwan 
with assessment accommodation and curriculum adjustment. The study also found that students with learning disabilities was the most dissatisfied group, followed by students with physical disabilities and students with multiple disabilities. It is supposed that students with different disabilities will require different types of assessment accommodation. This study aimed to explore whether students with different special learning needs needed different types of assessment accommodation.

One of the important purposes of assessment accommodation is to correctly evaluate students' learning performance. Mamiseishvili and Koch (2011) indicated that appropriate assessment accommodation was critical in order for students with disabilities to confidently continue studying. What is appropriate assessment accommodation? Many scholars have examined assessment efficiency using various learning performance variables (Richter \& Test, 2011). Learning performance is often used to evaluate the efficiency of appropriate assessment accommodation.

Chiu (2001) conducted a study with 278 teachers and found that $42.3 \%$ of primary school teachers and $59.1 \%$ of high school teachers had implemented assessment accommodation for students with disabilities, and $58.7 \%$ of these primary school teachers and $59.1 \%$ of secondary school teachers thought that what they were doing was appropriate. Bolt and Thurlow (2004) found that few teachers accommodate the assessments in practice. What is the reason why teachers did not appropriately accommodate the assessments for students? What assessment accommodate do the students need?

The history of special education in college in Taiwan is much shorter than in elementary and high schools. Moreover, unlike at primary and high school stages, college teachers are not required by the Education Ministry of Taiwan to have any special education training. Consequently, assessment accommodation is not yet very advanced in college. The special learning needs of college students with disabilities are diverse. This study explores assessment accommodation implemented in college based on the students' viewpoints. The study has two aims: (1) To explore the correlation between satisfaction with assessment implementation and learning performance for college students with disabilities. (2) To identify the assessment accommodation needs of students with various special learning needs. (3) To identify which elements of assessment accommodation implementation are correlated with positive learning performance for college students with various special learning needs.

\section{Literature Review}

\section{2-1 Assessing the Learning Performance of College Students with Disabilities}

Students with disabilities typically face many difficulties related to their academic performance. Mamiseishvili and Koch (2011) conducted a study of 1,910 first-year college students with disabilities and found that $24.6 \%$ of them failed to continue to their second year. Milson and Hartley (2005) pointed out 
that nearly half of all college students with disabilities (47\%) are suspended or drop out of school. Data from the National Centre for Educational Statistics pointed out that $11.3 \%$ of college students have disabilities and $7.5 \%$ of students have learning problems (Cressman \& Liljequist, 2012). Babbitt and White (2002) also identified serious challenges faced by this group: $50 \%$ of students with disabilities attended college but only $6.5 \%$ of them were still studying by their second college year.

Researches carried out in Taiwan also found that college students with disabilities experienced a number of learning difficulties. These students face different degrees of difficulty because of individual conditions relating, inter alia, to disability type and disability level (Chen, 2008; Sheu et al., 2002). Lin, Lo, and Chiu's investigation (2008) found that 1,260 students with disabilities withdrew from college in the 2004-2006 academic years in Taiwan. Lin et al. 's study also pointed out that subject difficulties were among the main reasons for dismissal from school (31.3\%). Academic distress is common among students with disabilities to study in their college studies.

The IDEA (Individuals with Disabilities Education Act) requires teachers to engage in academic accountability by assessment among all students with disabilities (IDEA, 2004). The assessments must reflect the students' learning progress. Mamiseishvili and Koch (2011) found that academic performance, academic expectations, and course attendance were significant predictors of whether a student would continue studying and get his/her bachelor's degree. In this study, curriculum involvement (including course attendance, curriculum interest and so on), and academic achievement (including academic grade ranking in the class, satisfaction with his/her learning achievement and so on) were selected as the two domains of a student's learning performance.

Scheduled and organisational assessments help teachers to define specific, rational learning standards so that students no longer feel helpless in relation to their learning, develop higher expectations about their academic achievement, and are more willing to study hard. In order to effectively assess and enhance learning performance, the assessment programme is usually arranged by communicating with students about their learning performance limitations and their needs with regard to assessment accommodation (Carter et al., 2009; Horowitz, Kaloi, \& Petroff, 2007; Repetto et al., 2011; Rous et al., 2010; Schutz, 2002; Summers et al., 2014).This requires an individualised assessment programme. One of the most important goals of developing assessment programmes is to understand the students' learning performance and support their academic progress. However, how exactly is students' learning performance correlated with assessment?

\section{2-2 Implementing Assessment Accommodation for College Students with Disabilities}

IDEA was amended to grant students with disabilities the right to participate in examinations and to be subject to fair and rational assessment arrangements. 
Many accommodation programmes are therefore subject to advocacy. IDEA specifies alternate assessments and assessment modifications as responses to the assessment obstacles caused by students' disabilities (Bolt \& Thurlow, 2004; Davis, 2010; Elliott et al., 2002). In order to address the difficulties and injustice that students with disabilities may face in examinations, Taiwan established the 'Examination Service Regulation for Students with Disabilities' (ESRSD) (2012) under the 'Special Education Act'.

Assessment accommodations are changes to assessment administration, test responses, or the assessments themselves that are offered to students with disabilities. Bolt and Thurlow (2004) pointed out that almost all students can participate fully in examinations with the typical assessment accommodation initiatives, such as alternating test forms or sites, but that $10 \%$ of students still need their assessments to be modified. Assessment activities that are responsive to student constraints and needs enable students with disabilities to participate effectively in assessment and to expect their academic achievement from teachers. According to IDEA, the school must appropriately evaluate the students' academic achievement and describe the needed assessment accommodation in each student's IEP (Individualised Educational Plan) (Chuang et al., 2010). Taiwan ESRSD stipulates that assessment accommodation for college students with disabilities should be described in their Individualised Support Plan (ISP). Assessment accommodation is a specialised, professional educational task. Proper assessment accommodation can provide meaningful academic support for students with disabilities designed based on the student's learning characteristics. Students with learning disabilities and visual impairments face many restrictions when it comes to reading, so they need pre-recorded audio tests or someone to read the examination items out loud. Also, if it takes longer than usual for a student to read questions, the number of exam questions could be reduced. The scores should be adjusted for students with severe hearing impairments in an English listening comprehension test. Students with blind have difficulties answering questions about colours, so these test items should be modified. As Fuchs, Fuchs, Eaton and Hamlett (2000) and Jordan (2009) reminded us: even if students have the same disability, they still have individualised academic performance needs. Teachers should have sufficient assessment knowledge to evaluate each student's limitations and then arrange individual assessment accommodations for him/her.

An inadequate understanding of students' characteristics may lead to ineffective assessment accommodations and incomplete understanding of their learning performance. The relevant personnel must display appropriate attitudes and awareness when conducting assessment accommodation. If the fairness of the assessment is questioned, this can cause teachers to hesitate to implement assessment accommodation, thereby endangering the rights of students with disabilities. What are the benefits of these assessment services for students' learning performance? Research data specifically about assessment accommodation could help to develop an appropriate assessment principle for college-level education. The present study intended to explore whether 
assessment accommodation implementation is correlated with positive learning performance for students with disabilities.

Actually, course teachers play a critical role in inclusive learning environment (Prater et al., 2014). Furthermore, Carter et al. (2017) identified that peer interactions can potentially increase academic engagement and social interaction, and improve learning within general education settings (Brock et al., 2016; Carter et al., 2015, 2017). Ensuring that students with disabilities can access this rich relationship will provide them with additional learning opportunities. Teachers and peers can thus potentially offer practical and promising academic support arrangements. This research surveys students' opinions about assessment accommodations, and supposes that learning interactions with teachers and peers should be considered in students' learning lives and assessment.

\section{Methods}

\section{3-1 Sampling}

There are 159 colleges in Taiwan. This study randomly sampled 30 of these colleges and then search for participants. Students with disabilities numbered 13,876 in the academic year in which this research was conducted. In this study, $2.88 \%$ (400) of the population was sampled and 288 college students with disabilities responded for the study. The subjects were categorized their special learning needs into sensory, physical, cognitive and others, according to their answers to three quantity and two open questions. The responses included some participants with more than two special learning needs and some without any special learning needs because their disabilities were mild. Finally, there were 308 occasions with special learning needs from 252 students (see Table 1). Among the categories, 88 had sensory special learning needs (visual or hearing), 106 had physical special learning needs, and 114 had cognitive special learning needs.

Table 1 : Demographics of this Research Sample

\begin{tabular}{cccc}
\hline \multicolumn{2}{c}{ Demographics } & $\mathrm{N}$ & $\%$ \\
\hline Gender & Male & 180 & 62.5 \\
& Female & 108 & 37.5 \\
Grade & Freshman & 81 & 28.1 \\
& Sophomore & 70 & 24.3 \\
& Junior & 69 & 24.0 \\
& Senior & 68 & 23.6 \\
\hline Total & & 288 & 100.0 \\
\hline Special learning needs* & Sensory & 88 & 28.6 \\
& Physical & 106 & 34.4 \\
& Cognitive & 114 & 37.0 \\
\hline
\end{tabular}

*Some samples cover more than two special learning needs

\section{3-2 Procedures}

The procedures were performed sequentially: (1) a questionnaire was developed and conducted with the sampled college students with disabilities after they signed a consent letter; (2) repeated reliability was evaluated by repeating scaling 
at 3-week intervals; (3) three professionals categorised samples by discussing and deducing their special learning needs; (4) a pilot study was conducted and found that assessment accommodations were weakly correlated with learning performance and that, by more literature review, learning interaction with teachers and peers for assessment should be considered critical correlated elements in students' learning performance; (5) a solid research design was created for this research; (6) the researchers analysed and selected the assessment accommodation needs indicated by the subjects with various special learning needs, and evaluated students' satisfaction with these needed assessment accommodations as the independent variables in the regression analysis.

\section{3-3 Instrument}

The questionnaire comprised three parts: (1) Subjects' demographic information. (2) The viewpoints of the students about assessment accommodation, which included two sub-parts: the first covering students' assessment accommodation needs, and the second addressing the extent to which the assessment accommodation satisfied the students' needs. This research covered 61 assessment accommodations under seven sub-categories of three domains: domain 1 included four typical assessment accommodations (test site adjustment, provision of auxiliary equipment / learning tools, test paper / test questions adjustment, answer mode adjustment), domain 2 included two assessment modifications (examination item modifications and score standard revision) and domain 3 included learning interaction with others for assessment. Domain 1 was developed with the assessment issued in ESRSD and domains 2 and 3 were suggested by seven special education experts. The score scale ranged from 1 to 5 points, and a higher score meant the students needed the accommodation more or were more satisfied with it. (3) Learning performance and satisfaction with assessment: to evaluate students' college learning performance, including curriculum involvement, academic achievement and assessment satisfaction. The score scale ranged from 1 to 5 points. The higher the score, the better the student's learning performance. The internal consistency reliability of the assessment accommodation was .85 to .96 , and the retest reliability was .73 to .84 .

\section{3-4 Data Analysis}

The data analysis was performed using frequency statistics and stepwise regression. Correlations were evaluated for learning performance and assessment satisfaction. The students' views on assessment accommodation needs were captured. The independent correlated variables of regression were examined with the degree of satisfaction about the needed assessment accommodations for students with various types of special learning needs. Considering that the standard deviation was large and would be neglected if the needs were examined by means alone, this research defined the needed assessment accommodation as the mean plus half of its standard deviation was greater than 3.50 . 


\section{Results}

\section{4-1 Correlations between Learning Performance and Assessment Satisfaction}

Table 2 shows that for the sample of 288 students, the relationship between learning performance and assessment satisfaction was significant: (1) curriculum involvement and academic achievement $(r=.43)$, learning interaction with others $(r=.52)$, and assessment satisfaction $(r=.52)$; (2) academic achievement and learning interaction with others $(r=.47)$, and assessment satisfaction $(r=.39)$; (3) learning interaction with others and assessment satisfaction $(r=.58)$. The $p$ values were all below .01. However, academic achievement and assessment satisfaction were correlated with comparatively a lower value. Among all the factors, academic achievement had the highest correlation with learning interaction with others.

Table 2 : The Correlation between Learning Performance and Assessment Satisfaction

\begin{tabular}{ccccc}
\hline & $\begin{array}{c}\text { Curriculum } \\
\text { involvement }\end{array}$ & $\begin{array}{c}\text { Academic } \\
\text { achievement }\end{array}$ & $\begin{array}{c}\text { Learning interaction } \\
\text { with others }\end{array}$ & $\begin{array}{c}\text { Assessment } \\
\text { satisfaction }\end{array}$ \\
\hline $\begin{array}{c}\text { Curriculum } \\
\text { involvement } \\
\text { Academic } \\
\text { achievement }\end{array}$ & 1 & $.43^{* * *}$ & $.52^{* * *}$ & $.52^{* * *}$ \\
$\begin{array}{c}\text { Interaction with } \\
\text { others } \\
\begin{array}{c}\text { Assessment } \\
\text { satisfaction }\end{array}\end{array}$ & - & 1 & $.47^{* * *}$ & $.39^{* * *}$ \\
\hline
\end{tabular}

${ }^{* * *} p<.001 ; n=288$

\section{4-2 Learning Performance of Students with Various Special Learning Needs} Table 3 shows that in general, students with physical special learning needs show higher levels of learning performance. Students with sensory and cognitive special learning needs display weaker learning performance. The differences among the students with diverse special learning needs were largest in academic achievement.

Table 3 : Learning Performance of Students with Various Special Learning Needs

\begin{tabular}{cccccc}
\hline \multirow{2}{*}{ Special learning needs } & \multicolumn{2}{c}{ Curriculum involvement } & & \multicolumn{2}{c}{ Academic achievement } \\
\cline { 2 - 3 } & $M^{*}$ & $S D$ & & & \multicolumn{2}{c}{$S D$} \\
\hline Sensory & 3.56 & 0.67 & & 2.93 & 0.85 \\
Physical & 3.68 & 0.78 & & 3.30 & 0.89 \\
Cognitive & 3.50 & 0.80 & & 2.99 & 0.95 \\
\hline Total & 3.58 & 0.76 & & 3.08 & 0.91 \\
\hline
\end{tabular}

*3.00 is the neutral values 


\section{4-3 Assessment Accommodations Needed by Students with Various Special Learning Needs}

Table 4 shows that there were 11 needed assessment accommodations among the students with sensory learning needs: extended test time, visual or acoustical reminders, permitted to ask the meaning of questions, weighting scores with other types of performance, scores adjusted by learning attitudes, scores adjusted by class attendance, provide item databases for exam, guidance teacher join the score evaluated, replace exam with paper report, and learning interaction with teacher, and with peers for assessment; There were four needed assessment accommodations among the students with physical special learning needs: extended test time, take tests on the ground floor or in a building with a lift, learning interaction with teachers and with peers for assessment; There were five needed assessment accommodations among the students with cognitive special learning needs: extended test time, scores adjusted by learning attitudes, scores adjusted by attendance, provide item databases to prepare for exams, guidance teacher join the score evaluated, and learning interaction with teachers and with peers for assessment. The results showed that learning interaction with teachers and with peers for assessment, and extended test time were popular needed assessment accommodations among all students with special learning need; and that students with sensory and cognitive special learning needs practically required an assessment modification. 


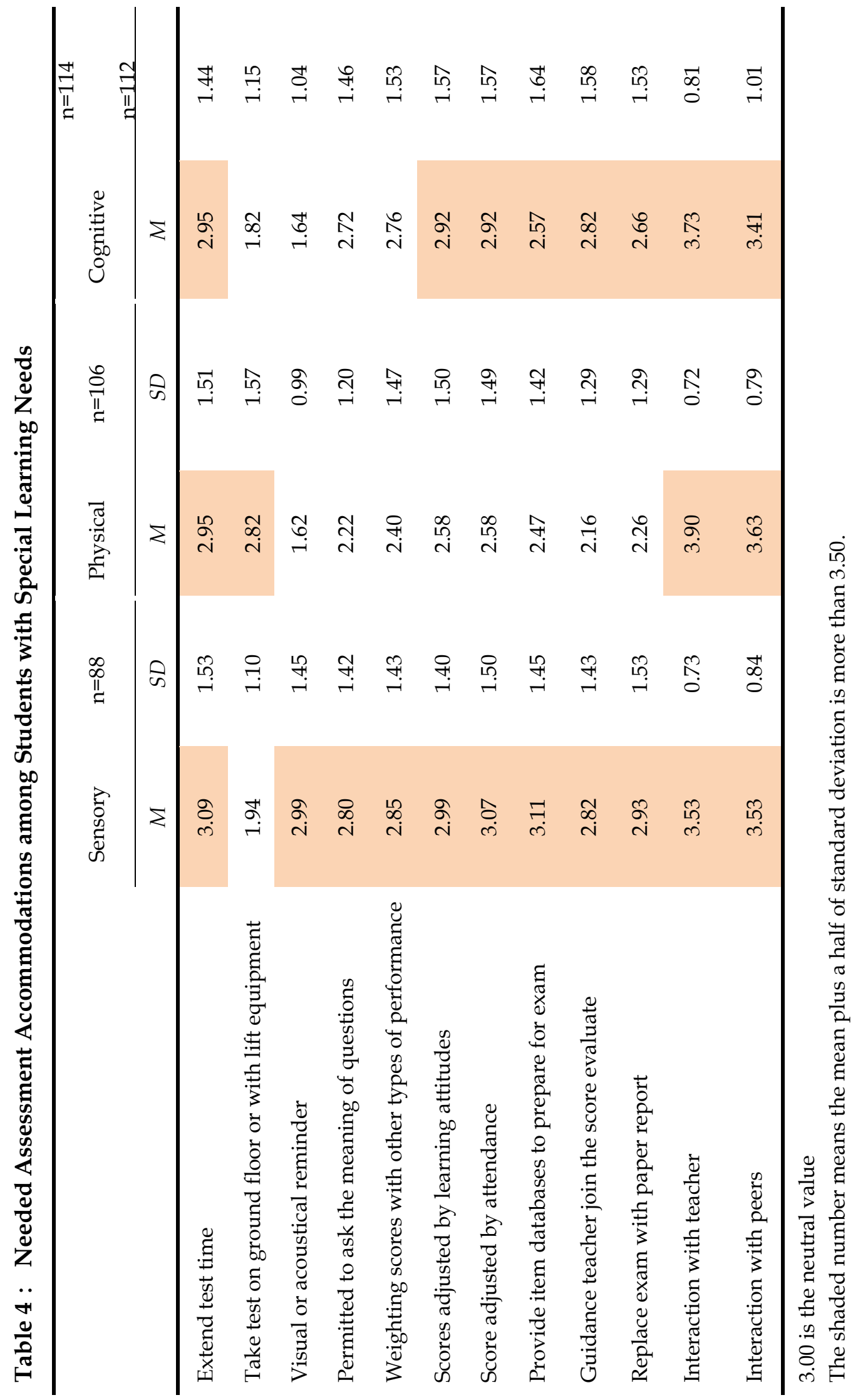


Table 5 : Stepwise Regression of Learning Performance for Students with Various Special Learning Needs

\begin{tabular}{|c|c|c|c|c|c|}
\hline Step & Variables entered in sequence & $\begin{array}{c}\text { Mult-R } \\
(\mathrm{R})\end{array}$ & $\mathrm{R}^{2}$ & $\begin{array}{c}\text { Non-S } \\
\beta\end{array}$ & $\mathrm{F}$ \\
\hline \multicolumn{6}{|c|}{ Students with Sensory Special Learning Needs } \\
\hline \multicolumn{6}{|c|}{ Curriculum Involvement } \\
\hline 1 & Learning interaction with teachers & .57 & .32 & .57 & $25.67 * * *$ \\
\hline 2 & Provide item datasets of the exam & .61 & .37 & -.23 & $15.75^{* * *}$ \\
\hline \multicolumn{6}{|c|}{ Academic Achievement } \\
\hline 1 & Learning interaction with teachers & .58 & .33 & .48 & $28.02 * * *$ \\
\hline 2 & $\begin{array}{c}\text { Students with Physical Special } \\
\text { Learning Needs }\end{array}$ & & & & \\
\hline \multicolumn{6}{|c|}{ Curriculum Involvement } \\
\hline 1 & Learning interaction with peers & .38 & .15 & .38 & $11.68^{* *}$ \\
\hline \multicolumn{6}{|c|}{ Academic Achievement } \\
\hline 1 & Learning interaction with teachers & .59 & .35 & .65 & $35.63^{* * *}$ \\
\hline \multicolumn{6}{|c|}{ Students with Cognitive Special Learning Needs } \\
\hline \multicolumn{6}{|c|}{ Curriculum Involvement } \\
\hline 1 & Learning interaction with teachers & .57 & .33 & .55 & $34.62^{* * *}$ \\
\hline \multicolumn{6}{|c|}{ Academic Achievement } \\
\hline 1 & Learning interaction with teachers & .51 & .26 & .56 & $24.00 * * *$ \\
\hline 2 & Extended test time & .55 & .30 & -.19 & $15.05^{\star * *}$ \\
\hline
\end{tabular}

$* * p<.01 .{ }^{* * *} p<.001$

\section{4-4 Critical Elements for Improving the Students' Learning Performance}

For the students with sensory special learning needs, two variables were significantly correlated with the students' curriculum involvement: learning interaction with their teachers, and provision of an item dataset to prepare for exams $(F=15.75, p<.001, \beta<.0)$. Learning interaction with teachers was correlated significantly with the students' academic achievement; For the students with physical special learning needs, learning interaction with peers was significantly correlated with the students' curriculum involvement and learning interaction with teachers was significantly correlated with the students' academic achievement; For the students with cognitive special learning needs, learning interaction with teachers was significantly correlated with the students' curriculum involvement. Two variables were significantly correlated with the students' academic achievement, namely learning interaction with teachers and extended test time $(F=15.05, p<.001, \beta<.0)$ (see Table 5).

\section{Discussion}

5-1 Correlation between Assessment Satisfaction and Learning Performance This study found that there were significant correlations between assessment satisfaction and different types of learning performance for college students with 
disabilities. However, the correlation values with academic achievement were low, while assessment satisfaction correlated more strongly with other types of learning performance, including curriculum involvment and learning interaction with others. This indicates that appropriate assessment implementation can help students to improve their learning performance. This study therefore posits that special education should endeavour to provide assessments that are responsive to students' needs.

\section{5-2 Students' Assessment Accommodation Needs}

Assessment accommodation needs vary depending on students' special learning needs. This finding is echoed in research by Milson and Hartley (2005) and Sheu et al. (2002). Milson and Hartley pointed out that students with different disability types face different obstacles in terms of their learning performance. Assessments should focus on multiple examination modes in order to accommodate students with various special learning needs. A single examination service cannot meet all assessment accommodation needs, and give rise to inaccurate, unfair and discriminatory results. Students with disabilities need individualised assessments.

As confirmed in this study, Spenceley and Wheeler (2016) indicated that extended test time is frequently requested and granted in assessment accommodation for students with disabilities. Moreover, this study found that assessment accommodation for students with physical special learning needs is fairly simple: extended test time and test sites be located on the ground floor. However, typical assessment accommodations cannot meet the assessment needs of students with sensory and cognitive special learning needs. Appropriate assessment modification strategies should be developed for them. However, Cho and Kingston (2013) research found that none of the teachers provided examinations for their students with disabilities that featured their grade-level content or other appropriate modifications. It is clear that support systems should be more actively developed being based on the students' needs and learning conditions.

\section{5-3 Elements Correlated with the Students' Learning Performance}

This study confirms Prater et al.'s (2014) point that accommodations are typically selected and implemented by course teachers. Learning interaction with teachers for assessment was significantly correlated with various types of learning performance among students with various special learning need. Ensuring that students with special learning need can access these learning opportunities within general education classrooms is an important but challenging task. This study corroborated the findings of other research in identifying teachers as playing an important role in the learning lives of students with disabilities (Sun \& Wu, 2016).

In this research, two types of accommodation satisfaction were correlated with students' performance: They include provision of an item dataset to prepare for exams with curriculum involvement for students with sensory special learning 
needs, and extended test time with academic achievement for students with cognitive special learning needs. However, their $\beta \mathrm{s}$ in the regression analysis were negative $(\beta=-.23$ and -.19). This means that some assessment accommodations were negatively correlated with the students' learning performance. A study found that special educators stated that their primary concern was students' low academic performance, so they made extended standard modifications in learning requirements (Cho \& Kingston, 2013). Davis (2010) indicated that assessment accommodations may hinder the ongoing process of instruction and do more harm than good by reinforcing lower expectations that can affect a student's academic achievement. Assessment modifications such as guidance teacher join the score evaluated, providing an item dataset to prepare for exams, or providing modified test content, may lower barriers in assessment; however, it is doubtful whether these accommodations serve to remediate the long-term effects on students' academic achievement. This concern is also relevant to the present study: it was found that these assessment accommodations did not improve the students' learning performance. Moreover, some of the accommodations even seemed to worsen the students' learning performance. College is a site where students' professional ability should be cultivated. This may be the reason why assessment modification is not a solid strategy in college environment.

\section{Suggestions}

Not using grade achievement ranking as the only learning performance indicator. It seems that compared to their peers, the academic achievement of the students with disabilities is inevitably restricted. If these students' learning performance is evaluated according to the standard academic grade ranking, they may feel helpless and feel that their efforts are not acknowledged. This may cause them to experience considerable setbacks in their study investment. It is recommended that learning attitudes and other pluralistic indicators should be used to strengthen the learning performance assessment of students with disabilities. Attention should be paid to students' endeavours to avoid frustration and improve their learning involvement with a view to enhancing their professional ability by encouraging them to compare their performance with their past achievement rather than to fixate on the general class grade ranking.

Develop assessment accommodation that take students' disabilities into consideration: This research found that students with special learning need, especially those with sensory and cognitive special learning needs, attained lower academic achievement in class. Learning barriers caused by disabilities create a need for different types of assessment accommodation. For student's expectancy towards their learning and to avoid learning helplessness, students with special learning needs need for assessment accommodation should be evaluated. Learning interaction with teachers for assessment should especially be the necessary consideration in the assessment process.

Improve teachers' assessment accommodation knowledge: Extended test time and some other assessment modifications are obviously needed by students with 
disabilities. However, they are not correlated with improved learning performance, and some are even negatively correlated with this. It suggests that when teachers implement assessment accommodations, they should offer other learning strategies and guide the students to keep positive learning performance; otherwise these initiatives may give rise to false expectations and less involvement in learning among the students. This study found that teachers play a critical role in making assessment for students. It is suggested that teachers should possess special education and assessment accommodation knowledge so that they can implement appropriate assessment accommodation; otherwise the work may be devoid of 'special education spirit'.

To provide guidelines for various assessment modifications implemented by regulation: Assessment regulations have a strong influence on campus assessment work. However, most of the regulations focus on typical assessment accommodations. The practice of assessment modification is not stipulated with clarity. The instructions remain unclear for teachers, with the result that they do not know how to implement effective assessment modifications. In addition to lowering the score standard, teachers should also implement other strategies, such as revising questions, increasing the simplicity of questions or setting fewer examination items. More concrete guidance about these aspects is needed in the relevant regulations.

To conduct further investigation research: This study explored various categories of students with disabilities by investigating students' views, but may have overlooked some of the learning characteristics of students with specific disabilities, for instance, learning disabilities, visual impairments, hearing impairments and others. Moreover, this research also neglected the teachers' views on assessment accommodation. Future research should conduct with course teachers and a more intensive assessment of students with specific disabilities.

Perform assessment modification studies: Typical assessment accommodation is not enough to perform a necessary evaluation of students with various special learning needs. Assessment accommodation with modifications have seldom been studied. More researches are needed on this to develop appropriate and rational assessment programmes they might implement and give teachers a set of assessment principles which they can follow.

Acknowledgments: The researcher would like to express sincere thanks to the Ministry of Science and Technology, Taiwan for funding this research. (No: MST107-2410- H-182- 009-SS2-)

\section{References}

Babbitt, B. C., \& White, C. M. (2002). R U ready? Helping students assess their readiness for postsecondary education. Teaching Exceptional Children, 35(2), 62-66. https://doi.org/10.1177/004005990203500209

Bolt, S. E., \& Thurlow, M. L. (2004). Five of the most frequently allowed testing accommodations in state policy. Remedial \& Special Education, 25(3), 141-152. 
https://doi.org/10.1177/07419325040250030201

Brock, M. E., Biggs, E. E., Carter, E. W., Cattey, G. N., \& Raley. K. S. (2016). Implementation and generalization of peer support arrangements for students with severe disabilities in inclusive classrooms. Journal of Special Education, 49(4), 221-232. https://doi.org/10.1177/0022466915594368

Carter, E. W., Trainor, A. A., Sun, Y., \& Owens, L. (2009). Assessing the transition related strengths and needs of adolescents with high-incidence disabilities. Exceptional Children, 76(1), 74-94. https:// doi.org/10.1177/001440290907600104

Carter, E. W., Moss, C. K., Asmus, J., Fesperman, E., Cooney, M., Brock, M. E., Lyons, G., Huber, H. B., \& Vincent, L. B. (2015). Promoting inclusion, social connections, and learning through peer support arrangements. Teaching Exceptional Children, 48(1), 9-18. https://doi.org/10.1177/0040059915594784

Carter, E. W., Gustafson, J. R., Sreckovic, M. A., Steinbrenner, J. R., Pierce, N. P., Bord, A., Stabel, A., Rogers, S., Czerw, A., \& Mullins, T. (2017). Efficacy of peer support interventions in general education classrooms for high school students with autism spectrum disorder. Remedial \& Special Education, 38(4), 207-221. https://doi.org/10.1177/0741932516672067

Chen, L. J. (2008). A study of the levels of living difficulty and supportive resource. Use for college students with disabilities. Bulletin of Special Education, 33, 25-54.

Chiu, S. C. (2001). The coping strategies of regular classroom teachers for the students with special needs. In the theory \& practice of remedial teaching (pp. 108-194). Taiwan National Kaohsiung Normal University Special Education Center (Ed.).

Cho, H. J., \& Kingston, N. (2013). Why IEP teams assign low performers with mild disabilities to the alternate assessment based on alternate achievement standards. Journal of Special Education, 47(3), 162-174. https://doi.org/10.1177/0022466911435416

Chuang, S. C., Hsieh, Y. W., \& Chu, M. C. (2010). The similarities and differences of the assessment accommodations for students with disabilities between the United States and Taiwan. Journal of Special Education EAssistive Technology, 5, 38-43.

Cressman, M. N., \& Liljequist, L. (2012). The effect of grade norms in college students: Using the Woodcock-Johnson Tests of Achievement. Journal of Learning Disabilities, 47(3), 271-278. https:// doi.org/10.1177/0022219412461052

Davis, H. T. P. (2010). Accommodating EBD: Do assessment accommodations reflect low expectations for students with EBD? Lynchburg, VaVA.: Liberty University. Retrieved from http:/ / files.eric.ed.gov/fulltext/ED510080.pdf

Elliott, S. N., McKevitt, B. C., \& Kettler, R. J. (2002). Test accommodations research and decision making: The case of good scores being highly valued but difficult to achieve for all students. Measurement and Evaluation in Counselling \& Development, $35,153-166$.

Examination Service Regulation for Student with Disabilities of 2012, Taiwan, $\S \$ 1010133145 \mathrm{C} 1400$ et seq.

Fuchs, L. S., Fuchs, D., Eaton, S. B., \& Hamlett, C. (2000). Using objective data sources to enhance teacher judgments about test accommodation. Exceptional Children, 67(1), 67-81. https://doi.org/10.1177/001440290006700105

Horowitz, S. H., Kaloi, L., \& Petroff, S. (2007). Transition to kindergarten. Policy implications for struggling learners and those who may be at risk for learning disabilities. New York, NY: National Center for Learning Disabilities.

Individuals with Disabilities Education Act (IDEA) of 2004, P. L.108-446, 20 U.S.C. $\$ \$ 1400$ et seq.

Jordan, A. S. (2009). Appropriate accommodations for individual needs allowable by state guidelines. ProQuest LLC, Dissertation, Cincinnati, OH: University of Cincinnati. 
Lin, K.T., Lo, C. S., \& Chiu, C. Y. (2008). The study of suspending schooling and leaving school for college student with special needs in Taiwan. Bulletin of Eastern Taiwan Special Education, 10, 1-19.

Mamiseishvili, K., \& Koch, L. C. (2011). First-to-second-year persistence of students with disabilities in secondary institutions in the United States. Rehabilitation Counselling Bulletin, 54(2), 93-105. https://doi.org/10.1177/0034355210382580

McMenamin, M. M., \& Zirke, P. A. (2003). OCR rulings under section 504 and the Americans with Disabilities Act: Higher education student cases. Journal on Postsecondary Education \& Disability, 16, 55-62.

Milson, A., \& Hartley, M. A. (2005). Assisting students with learning disabilities transitioning to college: What school counsellors should know? Professional School Counselling, 8, 436-441.

Prater, M. A., Redman, A. S., Anderson, D., \& Gibb, G. S. (2014). Teaching adolescent students with learning disabilities to self-advocate for accommodations. Intervention in School \& Clinic, 49, 298-305.

Repetto, J. B., McGorray, S. P., Wang, H., Podmostko, M., Andrews, W. D., Lubbers, J., \& Gritz, S. (2011). The high school experience: What students with and without disabilities report as they leave school. Career Development for Exceptional Individuals, 34(3), 142-152. https:// doi.org/10.1177/0885728811414699

Richter, S., \& Test, D. (2011). Effects of multimedia social stories on knowledge of adult outcomes and opportunities among transition-Aged youth with significant cognitive disabilities. Education and Training in Autism and Developmental Disabilities, 46, 410-442.

Rous, B., Hallam, R., McCormick, K., \& Cox, M. (2010). Practices that support the transition to public preschool programs: Results from a national survey. Early Childhood Research Quarterly, 25(1), 17-32. https://doi.org/10.1016/j.ecresq.2009.09.001

Schutz, P. F. (2002). Transition from secondary to postsecondary education for students with disabilities: An exploration of the phenomenon. Journal of College Reading $\mathcal{E}$ Learning, 33(1), 46-61. doi:10.1080/10790195.2002.10850136

Sheu, T. W., Shaow, C. T., Wu, S. S., Lin, H. Y., \& Chen, T. Y. (2002). The adjustment of campus life among university and college students with disabilities. Journal of Special Education, 16, 159-198.

Spenceley, L. M., \& Wheeler, S. (2016). The use of extended time by college students with disabilities. Journal of Postsecondary Education \& Disability, 29, 141-150 Summers, J. A., White, G. W., Zhang, E., \& Gordon, J. M. (2014). Providing support to postsecondary students with disabilities to request accommodations: A framework for intervention. Journal of Postsecondary Education \& Disability, 37, 245-260.

Sun, J. C. Y., \& Wu, Y. T. (2016). Analysis of learning achievement and teacher-student interactions in flipped and conventional classrooms. International Review of $\begin{array}{llll}\text { Research in Open } \mathcal{E} \text { Distributed Learning, 17(1), } & \text { 79-99. }\end{array}$ https://doi.org/10.19173/irrodl.v17i1.2116 